Published in final edited form as:

Behav Public Policy. 2017 November ; 1(2): 162-176. doi:10.1017/bpp.2016.15.

\title{
Educating good decisions
}

\author{
Ellen Peters \\ The Ohio State University
}

\begin{abstract}
Can we educate decision makers to make better decisions? In the present paper, I argue that we can in at least two broad ways: (1) teaching concrete knowledge about a specific decision or decision type and (2) teaching more abstract decision-making competencies thought to lead to better decisions. Teaching knowledge can be done using decision aids and similar techniques that provide important information about a specific choice (e.g., a medical treatment option). In these cases, information presented using evidence-based techniques to improve comprehension and use of information will have greater effects on judgments and choices. Teaching more abstract decision competencies, on the other hand, involves formal schooling (with the bulk of formal education falling during childhood) or training in a specific competency important to decision processes and outcomes; I use numeracy interventions as an exemplar.
\end{abstract}

"Knowledge is power. Information is liberating. Education is the premise of progress, in every society, in every family."

(Kofi Annan, 1997)

Recent policy trends have focused on tapping into the potential power of the informed consumer to make decisions that control costs and improve individual and societal outcomes. As a result, data are increasingly available to the public in medicine, finances, the environment, and elsewhere. In medicine, for example, informed decision making (defined as a process in which patients receive sufficient information about risks, benefits, limitations, alternatives, and uncertainties to make a value-concordant decision and participate in decision making at a desired level; Braddock et al., 1997, 1999) allows patients to take charge of their health by making good choices about consumer-directed health plans, surgical and other treatment risks, and evidence-based medicine. Research, in fact, demonstrates that these activated patients have better health outcomes and lower costs (Greene \& Hibbard, 2012; Greene et al., 2015; Ward et al., 2003). Patient engagement in medical decisions is critical because, in the end, it is the patient who has to take the medication once prescribed, who has to show up ready for surgery once it has been scheduled, and who has to make lifestyle changes to eating, exercise, and smoking once recommended. Patients, however, do not always follow medical advice on prescription medications; about 20-30\% are never filled and half of even ongoing chronic-disease medications are not taken as prescribed (Bosworth, 2012; Bosworth, Oddone, \& Weinberger, 2006; Osterberg \& Blaschke, 2005; Zullig, Shaw, \& Bosworth, 2014). And, of course, it's well known that large proportions of people don't follow eating, exercise, and smoking advice (Brownell \& Cohen, 1995; Wilfley \& Brownell, 1994; Abraham, Norman, \& Connor, 2000). This non-adherence is costly in terms of increased healthcare utilization and poorer 
outcomes. These are all good reasons to promote better informed and more activated patients. Similarly, in financial domains, consumers must protect themselves against payday loans and phishing schemes and prepare for their future through retirement savings. In environmental domains, public stakeholders are involved in protecting and ensuring appropriate uses of public goods such as parks, water, clean air, and climate.

A problem exists though in that not all individuals understand presented information either because the information is not presented in a comprehensible format and/or because the consumer's skills to make decisions in the domain are lower than preferred. In the present paper, I examine two broad ways of educating consumers to encourage better choices. An analogy exists to running hurdles in track (hurdling is the act of running and jumping over an obstacle at speed). Hurdling is difficult, but it can be made easier in either of two ways: You can make the hurdles shorter or you can make the runner stronger; either method will lead to greater success. The same thing is true of educating decisions: You can make the information easier to comprehend and use or you can improve the individual's decisionmaking competencies.

In the first part of the present paper, I consider knowledge-based educational interventions in decision making (e.g., decision aids), which promote deeper knowledge and/or make critical information more salient. These interventions are often used in medicine and elsewhere to promote informed decision making. When individuals access, understand, and use this information, they can increase control over their experiences and outcomes. However, the data are often confusing and overwhelming for lay people; therefore, I briefly review evidence-based strategies for how to present information to facilitate informed decision making. When information is presented strategically, decision makers can understand it better, use it more, and make more informed and value-concordant choices. Then, the second part of this paper questions whether knowledge is adequate on its own. Educating good decisions also may require the identification and teaching of competencies critical to effective decision making. In particular, I consider evidence for formal schooling (years of education) and specific numeracy training as long-term foundations for good decision making.

\section{Decision aids and other educational efforts to increase knowledge}

To improve decisions across a multitude of domains, researchers and policy makers have often considered short-term educational interventions to increase knowledge and improve particular decisions. For example, educational efforts have aimed to teach older adults how to prevent falls (Chang et al. 2004) and improve nutrition (Sahyoun, Pratt, \& Anderson, 2004). The medical-decision-making literature abounds with decision aids intended to improve knowledge in areas as diverse as prostate and colon cancer screening, hormone replacement therapy, male newborn circumcision, and rheumatoid arthritis (e.g., Fraenkel et al., 2012, 2015; O'Connor et al., 2003). Schroy et al. (2011), for example, developed a decision aid for colorectal cancer screening guided by constructs of the Ottawa Decision Support Framework (O'Connor et al., 1998, 1999). Colorectal cancer is the second leading cause of cancer-related death in the U.S. and the third most commonly diagnosed cancer, but $50 \%$ of eligible Americans do not get appropriate screening (Shapiro, et al., 2008). The 
decision aid was designed with an audiovisual and touch-screen format to simplify use for individuals with limited literacy or computer skills and was comprised of a series of modules in which diverse, professional actors played roles and conveyed relevant information via onscreen video, animation, and/or graphics. One module, for example, was comprised of brief descriptions of five recommended screening methods whereas another included audio and visual (i.e., traffic light graphic) comparisons of each screening method with respect to individual test features (e.g., test accuracy, inconvenience, possible complications). The comparisons were intended to allow patients to more easily understand the differences between screening options (e.g., for test accuracy). We also explicitly included a noscreening option to educate patients on the difference in risk between getting versus not getting screened (regardless of what screening method they chose). With exposure to the decision aid compared to no exposure, knowledge, satisfaction with choice, and intentions to get screened were all higher. In other words, informing choices helped. Indeed, exposure to decision aids generally increases knowledge and decreases decisional conflict in medical choices (O'Connor et al., 2003).

Policy makers, however, need to be aware that how options and information are presented matters to consumer comprehension and use of that information. Providing the right facts is not enough; information providers also need to provide those facts in a comprehensible and easy-to-evaluate manner so that complex content can be understood and used by decision makers. In particular, five evidence-based communication strategies have been shown to facilitate comprehension and use of appropriate information (see Table 1 and, for more detailed explanation, Peters, Meilleur, \& Tompkins, 2014).

\section{Graphic warning labels increase knowledge}

The use of graphic warning labels on cigarette packages can be used as an exemplar of a communication that uses many of these evidence-based practices in an attempt to combat a worldwide smoking habit. According to the US Centers for Disease Control (2016), smoking harms nearly every organ of the body, and it is the leading cause of preventable death in the US, with more than 480,000 smoking-related deaths per year. The average smoker dies 10 years earlier than the average non-smoker. In addition, more than 16 million Americans live with smoking-related disease. This means that, for every person who dies because of smoking, at least 30 people live with a serious smoking-related illness such as cancer, heart disease, stroke, lung diseases, diabetes, and chronic obstructive pulmonary disease (COPD), which includes emphysema and chronic bronchitis, tuberculosis, certain eye diseases, problems of the immune system, including rheumatoid arthritis, and erectile dysfunction in males. In addition, if smoking rates do not change, 1 in 13 young Americans ( $<=17$ years) alive today are expected to die from smoking-related disease. However, quitting can have marked benefits. Adults who quit smoking at 25 to 34,35 to 44 , or 45 to 54 years of age are expected to gain about 10, 9, and 6 years of life, respectively, as compared to those who continued to smoke (Jha et al., 2013).

Smokers have some knowledge of these major health risks (Kenkel \& Chen, 2000; Kennedy et al., 2011), but in-depth knowledge of tobacco's health risks is low (Smith et al., 2011). Research shows that most people can name only 1-2 of the many diseases caused by 
smoking (Weinstein et al., 2004). Little knowledge exists about numeric likelihoods of smoking-related disease, and most adults and adolescents overestimated the likelihood that lung cancer is curable (Weinstein, Marcus, \& Moser, 2005). Adolescents' risk understanding and perceptions appear to be lower than those of adults (Kenkel \& Chen, 2000; Slovic, 2001; US Department of Health \& Human Services, 1994). Tobacco users also minimize personal risk and demonstrate an "optimistic bias" (Weinstein, Marcus, \& Moser, 2005; Weinstein, 1998; but see Viscusi, 2000; Dillard, McCaul, \& Klein, 2006).

Graphic warning labels on cigarette packs are one educational intervention being used in at least 100 countries worldwide (Canadian Cancer Society, 2016). Their use takes advantage of four of the five evidence-based strategies in Table 1. First, they have identified a communication goal to increase knowledge and decrease smoking. Second, the use of graphic images to supplement more complicated text may reduce cognitive effort in understanding smoking-related disease, perhaps helping less educated populations the most (Niederdeppe et al., 2008). Third, the graphic warnings provide affective meaning to smoking-related diseases that are otherwise potentially abstract and meaningless to smokers (Kees et al., 2010; Peters et al., 2007). This affective meaning may promote a series of cognitive and behavioral responses that influence smoking knowledge, perceptions, and behavior (Peters, 2006). Finally, the graphic warnings draw more attention than text-only warnings (Strasser et al., 2012). However, until recently, graphic warnings had been studied only in surveys and small experimental studies with limited exposures to the warning labels.

In the first randomized clinical trial of smokers in a naturalistic setting, Evans et al. (2015) found that, compared to text-only warnings, placing graphic warnings on smokers' cigarette packages each week for four weeks: 1) increased negative affect to smoking; 2) heightened scrutiny of smoking's risks; 3 ) improved the perceived credibility of the warnings; and 4) increased label memory. The increased knowledge mediated effects of the graphic warnings on increased risk scrutiny and perceived credibility. Additional indirect-only effects ensued on heightened risk perceptions, quit intentions, and risk knowledge. Overall, emotional reactions to the warnings helped smokers to understand the risks of their habit better and encouraged them to quit. A later, larger clinical trial demonstrated that graphic warnings indeed increased quitting (Brewer et al., 2016).

These results have implications for graphic-warning policy and also for how behavioral scientists can work with law makers so that research into the effectiveness of educational interventions does not get "lost in translation" in the legal process (Peters et al., 2016). In the case of graphic warnings, the US courts reasoned that graphic warnings cued emotional responses, and therefore, could not be considered "factual." They did not consider, however, the warnings' multiple psychological effects on risk education. Emotional influences on cognition, although not always appreciated by law and policy makers, are deeply rooted in human evolutionary history (Blanchette et al., 2016). Behavioral scientists can work with attorneys and others to interpret and apply behavioral research effectively. 


\section{Formal schooling and numeracy interventions}

The interventions discussed thus far assume that more knowledge leads inevitably to better decisions and outcomes. However, knowledge may not always be enough because decision makers need to think and reason about facts, be motivated by their meaning, and be able to quell short-term desires and overcome mindless habits. For example, knowing that smoking is bad and exercise is good often does not affect change. One can also know that purchasing $\$ 40$ a day in lottery tickets is unlikely to yield the big winner but hope that it might (and continue to buy tickets). As a result, in my lab we have recently become interested in the role of education - formal schooling (the number of years spent in school) and more specific numeracy training with adults - and their potential effects on decision-making competencies as a back door towards improving decision making. Education interventions that build adult capacity may better allow decision makers to bring knowledge to bear on decisions, think probabilistically, use heuristic processing less, and consider alternative scenarios.

\section{Formal education and improvements to health and wealth}

Formal education is widely acknowledged to have "silver bullet" properties on health and wealth. But why and how does education have these positive effects? To start to examine this question, we went to rural areas in sub Saharan Africa in the eastern side of Ghana and to the highlands of Peru where the Quechua peoples live. We chose these places in order to study the decision-making and health effects of greater schooling in populations with fewer issues of selection bias and endogeneity than what we can find in more developed countries (for obvious reasons, we cannot randomly assign children to years of education). Individuals in these areas varied widely in terms of their years of formal education, but shared similar histories in terms of parental educational levels and post-schooling employment; their reasons for continuing or discontinuing schooling also appeared to be non-academic (e.g., individuals indicated the need to quit schooling because a family injury occurred and they were needed on the farm or in the home).

We were particularly interested in education's potential effects on the problem of HIV/AIDS in these two countries. Numerous international NGOs, particularly in sub Saharan Africa, have developed and distributed HIV/AIDS prevention education curricula; they have tried to build knowledge although the facts have not always been interpreted correctly. For example, during our pilot data collection in Ghana, when an unschooled, middle-aged, rural man was asked whether blood transfusions could infect him with HIV; he responded, "yes, but not if I wear a condom." The quote illustrates a gap in basic understanding of and reasoning with the facts associated with HIV transmission despite attempts to increase knowledge.

We proposed and tested a schooling-decision-making model, positing that formal education would foster intellectual abilities and, in turn, provide individuals with enduring cognitive and decision-making competencies to support better health-related behaviors (Peters et al., 2010). In a field study with 181 adults in rural Ghana, we examined health-protective behaviors related to HIV/AIDs infection, one of Ghana's critical health issues. As expected, individuals with more years of formal education practiced more protective health behaviors (e.g., Have you ever been tested for HIV/AIDs; used a condom; spoken with your spouse or partner about HIV/AIDs?). More years of schooling were also correlated, as expected, with 
greater wealth and HIV/AIDs knowledge as well as greater cognitive, numeracy, and decision-making abilities. However, structural-equation-modeling analysis demonstrated that it was the education-enhanced abilities (and not HIV/AIDS knowledge or wealth) that mediated the effects of education on taking health-protective behaviors. Schooling appeared to matter, at least in part, because it built decision-making capacity.

A later study of 247 individuals living in rural areas of the Peruvian Highlands focused on objective numeracy (ability with numbers) and one HIV/AIDs-related protective behavior, condom use (Dieckmann et al., 2015). Similar to our results from Ghana, these results again supported the schooling-decision-making model, and also showed a potential unique protective effect of objective numeracy (defined as the ability to comprehend and use probabilistic and other mathematical concepts) on this health-protective behavior even after accounting for other measures of fluid intelligence and potential confounding factors. Schooling appears to enhance cognitive and decision competencies that are then brought to bear on better decisions. Identifying causal mechanisms that underlie these effects (beyond increases to years of formal education) would help us translate this knowledge into effective health interventions that could be used with adults. Based on Dieckmann et al.'s results, numeracy, in particular, may be important to taking protective action against future potential risks, perhaps through the more numerate's ability to recall and understand the meaning of risk likelihoods better (Peters, 2012). These abilities may allow them to forecast better into the future and balance risks and benefits more appropriately.

\section{Numeracy interventions improve judgments and decision outcomes}

In our formal-education field studies in Ghana and Peru, more schooling was associated with greater objective numeracy, which was linked with better decision abilities in the Ghana study and with reports of more health-protective behaviors in both studies. In developed countries, greater objective numeracy has been linked with a wide variety of better health outcomes including superior control of stroke risk and diabetes and lower Body Mass Index (Cavanaugh et al., 2008; Estrada et al., 2004; Ghazal, Cokely, \& Garcia-Retamero, 2014; Peters et al., 2006; Huizinga et al., 2008; Reyna et al., 2009). More numerate individuals also do better financially by having more adequate retirement savings, avoiding predatory loans, and paying credit cards in full (Banks \& Oldfield, 2007; Lusardi \& Mitchell, 2014; Sinayev \& Peters, 2015). In addition, more objectively numerate individuals appear to use better decision processes such that, compared to the less numerate, the more numerate comprehend numbers better in decisions, use them more, and use non-numeric information less. The more numerate also attend more to numeric information and derive greater affective meaning from numeric information (they report stronger positive and negative affect to numeric information, and this affective meaning appears to underlie their greater use of numbers; Peters et al., 2006; Petrova, van der Pligt, \& Garcia-Retamero, 2014). Because numbers are present, implicitly or explicitly, in many of the judgments we form and decisions we make, people who are more successful at solving numeracy problems make better decisions and enjoy better outcomes, presumably as a result of their superior decisionmaking abilities. 
Numeracy's causal effects on decision quality had not been tested until recently, but the combination of results reviewed in the present paper suggests that training objective numeric ability in adults could improve decision competencies as well as outcomes. Numeracy also may be one of the more modifiable cognitive abilities, at least as compared to components of fluid intelligence such as working memory (Redick et al., 2013; Shipstead, Redick, \& Engle, 2012). We recently examined two methods to experimentally alter numeracy to test causal effects of numeracy for improving decision making.

Approximate arithmetic practice-Dieckmann et al. (2015) found that objective numeracy, in particular, was associated with greater condom usage, a health behavior protective against HIV/AIDs risk. Numeracy may be associated with such protective behaviors because greater numeracy is linked with superior risk understanding (Petrova et al., 2013; Sinayev \& Peters, 2015). Chesney and Peters (in review) tested this relation causally by improving adult numeracy and testing whether such improvements led to greater consistency in risk perceptions. Participants were randomly assigned to practice either arithmetic or working-memory problems in six sessions over a two-week period. Arithmetic participants were asked to quickly estimate the sum of OR difference between presented numeric stimuli, using symbolic numbers (i.e., Arabic number) OR non-symbolic numeric stimuli (i.e., dot arrays). The training was dynamic, becoming more difficult when participants answered correctly, and less difficult when participants answered incorrectly. Compared to the working-memory training condition, both symbolic and non-symbolic approximate arithmetic practice improved objective numeracy and caused greater consistency in risk perceptions as hypothesized (e.g., they perceived their five-year mortality risk as greater than or equal to their one-year risk rather than the reverse). The benefits of non-symbolic training were similar to the more familiar symbolic training, but non-symbolic training yielded greater numeracy benefits among individuals who believed they had lower numeric skills (based on subjective numeracy scores; Fagerlin et al., 2007) whereas symbolic training resulted in greater numeracy improvements among those who believed they had higher numeric skills.

Improving numeracy through values affirmation-In Chesney and Peters (in review), we attempted to improve objective numeracy skills directly through training sessions in which participants practiced arithmetic. In a second study, we instead attempted to manipulate numeracy indirectly (Peters et al., in review). In particular, our participants were students in a psychology statistics course in which we conducted a values-affirmation intervention intended to improve subjective numeracy (beliefs in one's numeric abilities) and, through it, enhance objective numeracy and, ultimately, decision outcomes. In prior research, taking a statistics course improved one aspect of decision making (use of the law of large numbers, Fong, Krantz, \& Nisbett, 1986). However, taking math courses, including the present statistics course, involves difficult concepts and negative feedback, which can pressure students considerably (depending on how well student learning is supported), reduce their self-efficacy, and interfere with learning (Betz \& Hackett, 1983; Hackett \& Betz, 1981). A theoretically motivated psychological intervention, called values affirmation (Cohen, Garcia, Apfel, \& Master, 2006; Miyake et al., 2010), in which people reflect on core values, can focus people on long-term goals over immediate pressures (Logel \& Cohen, 
2012; Schmeichel \& Vohs, 2009) and increase acceptance of counter-attitudinal thoughts (Sherman \& Cohen, 2006), including perhaps beliefs in numeric ability (Hall et al., 2014). Our primary hypothesis concerned the intervention's possible snowball effects; we expected the intervention to increase subjective and objective numeracy and, through them, improve the quality of financial literacy as well as financial and health outcomes (e.g., having a savings account or emergency fund; [not] having sex in a non-committed relationship without using a condom). Such a result would support the importance of learning abstract numeric skills. In a 9-week longitudinal study (Peters et al., in review), undergraduate students taking a psychology statistics course were randomly assigned to a control condition or a values-affirmation manipulation intended to improve numeracy. By the final week in the course, the numeracy intervention had enhanced objective numeracy, subjective numeracy, and two decision-related outcomes (financial literacy and health outcomes). It also showed positive indirect-only effects on financial outcomes and a series of math-course-related outcomes (course grades, intentions to take more math-intensive courses, later mathintensive courses taken based on academic transcripts). All decision and math-course-related outcome effects were mediated by the changes in objective and/or subjective numeracy and demonstrated similar and robust enhancements. Consistent with our hypotheses, improvements to abstract numeric reasoning improved decision outcomes.

\section{Conclusions}

Educational interventions can focus either on increasing knowledge (e.g., through a decision aid) or improving abstract decision-related competencies (e.g., through more years of formal schooling or numeracy training). We know that we can improve informed decision making using decision aids and similar means that are focused on improving knowledge. We also know that information providers, including policy makers, will inevitably influence consumer decisions (and not just increase knowledge) through how and what they choose to present. These presentation choices can be made intuitively or in an evidence-based manner with the best interests of the decision maker in mind. The choices involve ethical considerations and, therefore, require careful attention.

We also know that educational interventions tend to work better in children, and particularly in preschoolers where educational policies have the biggest "bang for the buck" (Heckman, 2007). However, the numeracy-training interventions reviewed here showed early promise in adults. They had small effects, but effects that may be long lasting. In Peters et al. (in review), an affirmation intervention conducted within a statistics course required two 10-15 minute writing exercises and improved health outcomes and financial literacy eight weeks later. In Chesney and Peters (in review), a more involving numeracy intervention (6 sessions of 20-30 minutes each) resulted in more individuals being consistent in their risk perceptions two weeks after the initial training.

Other types of educational interventions exist too. For example, Reyna, Weldon, and McCormick (2015) reviewed evidence that teaching adolescents to automatically associate particular contextual cues with appropriate actions resulted in decreasing sexual risk taking and increasing medication adherence. Decision making as a set of core skills may be teachable as well (Baron \& Brown, 1991). Training decision making itself, either directly or 
indirectly (e.g., through formal schooling or numeracy training), may improve quality of life across multiple domains.

Schooling (as opposed to knowledge interventions such as decision aids) is not a low-touch intervention, but it is important. Education in math may be particularly important. The 2010 ACT College and Career Readiness report found only $29 \%$ of the tested 2010 graduates are considered college-ready in science and $43 \%$ are considered college-ready in math. The heart of Science Technology Engineering and Math (STEM) education is better jobs, workforce development and innovation, improved economy for our nation, and better global leadership. But this way of thinking about STEM education leaves out a lot of people who perhaps don't see how they fit into these large concepts and, therefore, why they or their children would benefit from more STEM education. The educational research presented here, however, suggests that STEM education concerns everyone. It is about everyday people, the quality of their numeric and decision competencies, and the health, wealth, and other outcomes they experience.

\section{Acknowledgments}

The writing of this paper was supported by funding from the National Science Foundation (SES-1155924 and -1558230) and the National Cancer Institute and FDA Center for Tobacco Products (CTP) (grant number P50CA180908). The content is solely the responsibility of the author and does not necessarily represent the official views of any funder. Table 1 was modified with permission from "Numeracy and the Affordable Care Act: Opportunities and Challenges", Appendix A, Health Literacy and Numeracy: Workshop Summary, 2014 by the National Academy of Sciences, Courtesy of the National Academies Press, Washington, DC.

\section{References}

Abraham, C, Norman, P, Conner, M. Understanding and changing health behaviour: From health beliefs to self-regulation. Hove, UK: Psychology Press; 2000.

Annan, Kofi. [29 November 2016] United Nations Press Release SG/SM/6268. 1997. Jun 23, http:// www.un.org/press/en/1997/19970623.sgsm6268.html

Banks J, Oldfield Z. 2007Understanding pensions: Cognitive function, numerical ability and retirement saving. Fiscal Studies. :143-170.

Baron, J, Brown, RV. Teaching decision making to adolescents. Hillsdale, NJ: Erlbaum; 1991.

Betz NE, Hackett G. 1983; The relationship of mathematics self-efficacy expectations to the selection of science-based college majors. Journal of Vocational Behavior. 23(3):329-345.

Blanchette I, Marzouki Y, Claidière N, Gullstrand J, Fagot J. 2016Emotion-Cognition Interaction in Nonhuman Primates Cognitive Avoidance of Negative Stimuli in Baboons (Papio papio). Psychological Science.

Bosworth HB. 2012; How can innovative uses of technology be harnessed to improve medication adherence? Expert Review of Pharmacoeconomics \& Outcomes Research. 12(2):133-135. [PubMed: 22458612]

Bosworth, HB, Oddone, EZ, Weinberger, M, editorsPatient treatment adherence: concepts, interventions, and measurement. Hove, UK: Psychology Press; 2006.

Braddock CH III, Edwards KA, Hasenberg NM, Laidley TL, Levinson W. 1999; Informed decision making in outpatient practice: time to get back to basics. Jama. 282(24):2313-2320. [PubMed: 10612318]

Braddock CH, Fihn SD, Levinson W, Jonsen AR, Pearlman RA. 1997; How doctors and patients discuss routine clinical decisions - Informed decision making in the outpatient setting. Journal of General Internal Medicine. 12(6):339-345. [PubMed: 9192250] 
Brewer NT, Hall MG, Noar SM, Parada H, Stein-Seroussi A, Bach LE, Hanley S, Ribisl KM. 2016; Effect of Pictorial Cigarette Pack Warnings on Changes in Smoking Behavior: A Randomized Clinical Trial. JAMA Internal Medicine. doi: 10.1001/jamainternmed.2016.2621

Brownell KD, Cohen LR. 1995; Adherence to dietary regimens 1: An overview of research. Behavioral Medicine. 20(4):149-154.0. [PubMed: 7620226]

Canadian Cancer Society. [Accessed December 7, 2016] Cigarette Package Health Warnings: International Status Report. 52016. http://www.tobaccolabels.ca/wp/wp-content/uploads/2016/11/ Cigarette-Package-Health-Warnings-International-Status-Report-English-CCS-Oct-2016.pdf healthwarningsinfo/statusreport/

Cavanaugh K, Huizinga MM, Wallston KA, Gebretsadik T, Shintani A, Davis D, Gregory RP, Fuchs L, Malone R, Cherrington A, Pignone M. 2008; Association of numeracy and diabetes control. Annals of Internal Medicine. 148(10):737-746. [PubMed: 18490687]

Chang JT, Morton SC, Rubenstein LZ, Mojica WA, Maglione M, Suttorp MJ, Roth EA, Shekelle PG. 2004; Interventions for the prevention of falls in older adults: Systematic review and meta-analysis of randomized clinical trials. British Medical Journal. 328:680-7. [PubMed: 15031239]

Chesney D, Peters E. The causal impact of numeracy on judgments: Improving numeracy via symbolic and non-symbolic arithmetic practice improves risky judgments.

Cohen GL, Garcia J, Apfel N, Master A. 2006; Reducing the racial achievement gap: A socialpsychological intervention. Science. 313(5791):1307-1310. [PubMed: 16946074]

Dieckmann NF, Peters E, Leon J, Benavides M, Baker DP, Norris A. 2015; The role of numeracy and fluid intelligence in sex-related protective behaviors. Current HIV Research. 13(5):337-346. [PubMed: 26149157]

Dillard AJ, McCaul KD, Klein WM. 2006; Unrealistic optimism in smokers: Implications for smoking myth endorsement and self-protective motivation. Journal of Health Communication. 11(S1):93102.

Estrada CA, Martin-Hryniewicz M, Collins C, Byrd JC, Peek BT. 2004; Literacy and numeracy skills and anticoagulation control. The American Journal of the Medical Sciences. 328(2):88-93. [PubMed: 15311167]

Evans AT, Peters E, Strasser AA, Emery LF, Sheerin KM, Romer D. 2015; Graphic Warning Labels Elicit Affective and Thoughtful Responses from Smokers: Results of a Randomized Clinical Trial. PloS One. 10(12):e0142879. [PubMed: 26672982]

Fagerlin A, Zikmund-Fisher BJ, Ubel PA, Jankovic A, Derry HA, Smith DM. 2007; Measuring numeracy without a math test: development of the Subjective Numeracy Scale. Medical Decision Making. 27(5):672-680. [PubMed: 17641137]

Fong GT, Krantz DH, Nisbett RE. 1986; The effects of statistical training on thinking about everyday problems. Cognitive Psychology. 18(3):253-292.

Fraenkel L, Matzko CK, Webb DE, Oppermann B, Charpentier P, Peters E, Reyna V, Newman ED. 2015; Use of decision support for improved knowledge, value clarification and informed choice in rheumatoid arthritis. Arthritis Care \& Research. 67(11):1496-1502. [PubMed: 26195173]

Fraenkel L, Peters E, Charpentier P, Olson B, Errante L, Schoen R, Reyna V. 2012; A decision tool to improve the quality of care in rheumatoid arthritis. Arthritis Care \& Research. 64(7):977-985. [PubMed: 22392766]

Ghazal S, Cokely ET, Garcia-Retamero R. 2014; Predicting biases in very highly educated samples: Numeracy and metacognition. Judgment and Decision Making. 9(1):15.

Greene J, Hibbard JH. 2012; Why does patient activation matter? An examination of the relationships between patient activation and health-related outcomes. Journal of General Internal Medicine. 27(5):520-526. [PubMed: 22127797]

Greene J, Hibbard JH, Sacks R, Overton V, Parrotta CD. 2015; When patient activation levels change, health outcomes and costs change, too. Health Affairs. 34(3):431-437. [PubMed: 25732493]

Hackett G, Betz NE. 1981; A self-efficacy approach to the career development of women. Journal of Vocational Behavior. 18(3):326-339.

Hall CC, Zhao J, Shafir E. 2014; Self-affirmation among the poor: Cognitive and behavioral implications. Psychological Science. 25(2):619-625. [PubMed: 24357617] 
Heckman JJ. 2007; The economics, technology, and neuroscience of human capability formation. Proceedings of the National Academy of Sciences. 104(33):13250-13255.

Huizinga MM, Beech BM, Cavanaugh KL, Elasy TA, Rothman RL. 2008; Low numeracy skills are associated with higher BMI. Obesity. 16(8):1966-1968. [PubMed: 18535541]

Jha P, Ramasundarahettige C, Landsman V, Rostron B, Thun M, Anderson RN, McAfee T, Peto R. 2013; 21st-century hazards of smoking and benefits of cessation in the United States. New England Journal of Medicine. 368(4):341-350. [PubMed: 23343063]

Kees J, Burton S, Andrews JC, Kozup J. 2010; Understanding how graphic pictorial warnings work on cigarette packaging. Journal of Public Policy \& Marketing. 29(2):265-276.

Kenkel, DS, Chen, L. Consumer information and tobacco use. In: Jha, P, Chaloupka, FJ, editorsTobacco control in developing countries. Oxford: Oxford University Press; 2000. 177-214.

Kennedy RD, Spafford MM, Parkinson CM, Fong GT. 2011; Knowledge about the relationship between smoking and blindness in Canada, the United States, the United Kingdom, and Australia: results from the International Tobacco Control Four-Country Project. Optometry-Journal of the American Optometric Association. 82(5):310-317.

Logel C, Cohen GL. 2012; The role of the self in physical health: Testing the effect of a valuesaffirmation intervention on weight loss. Psychological Science. 23(1):53-55. [PubMed: 22157517]

Lusardi A, Mitchell OS. 2014; The economic importance of financial literacy: Theory and evidence. Journal of Economic Literature. 52(1):5-44. [PubMed: 28579637]

Miyake A, Kost-Smith LE, Finkelstein ND, Pollock SJ, Cohen GL, Ito TA. 2010; Reducing the gender achievement gap in college science: A classroom study of values affirmation. Science. 330(6008): 1234-1237. [PubMed: 21109670]

Niederdeppe J, Fiore MC, Baker TB, Smith SS. 2008; Smoking-cessation media campaigns and their effectiveness among socioeconomically advantaged and disadvantaged populations. American Journal of Public Health. 98(5):916-924. [PubMed: 18381998]

O'Connor AM, Stacey D, Entwistle V, Llewellyn-Thomas H, Rovner D, Holmes-Rovner M, Tait V, Tetroe J, Fiset V, Barry M, Jones J. 2003; Decision aids for people facing health treatment or screening decisions (Cochrane Review). The Cochrane Library. 2

O'Connor AM, Drake ER, Fiset V, Graham ID, Laupacis A, Tugwell P. 1998; The Ottawa patient decision aids. Effective Clinical Practice: ECP. 2(4):163-170.

O'Connor AM, Tugwell P, Wells GA, Elmslie T, Jolly E, Hollingworth G, McPherson R, Bunn H, Graham I, Drake E. 1999; A decision aid for women considering hormone therapy after menopause: decision support framework and evaluation. Patient Education and Counseling. 33(3): 267-279.

Osterberg L, Blaschke T. 2005; Adherence to medication. New England Journal of Medicine. 353(5): 487-497. [PubMed: 16079372]

Peters, E. The functions of affect in the construction of preferences. In: Lichtenstein, S, Slovic, P, editorsThe Construction of Preferenc. New York: Cambridge University Press; 2006. 454-463.

Peters E. 2012; Beyond comprehension: The role of numeracy in judgments and decisions. Current Directions in Psychological Science. 21(1):31-35.

Peters E, Baker DP, Dieckmann NF, Leon J, Collins J. 2010; Explaining the effect of education on health a field study in Ghana. Psychological science. 21(10):1369-1376. [PubMed: 20739672]

Peters E, Evans AT, Hemmerich N, Berman M. 2016; Emotion in the law and the lab: The case of graphic cigarette warnings. Tobacco Regulatory Science. 2(4):404-413. [PubMed: 29057296]

Peters, E, Meilleur, L, Tompkins, MK. Health Literacy and Numeracy: Workshop Summary. Washington, DC: The National Academies Press; 2014. Numeracy and the Affordable Care Act: Opportunities and challenges. Appendix A. IOM (Institute of Medicine).

Peters E, Romer D, Slovic P, Jamieson KH, Wharfield L, Mertz CK, Carpenter SM. 2007; The impact and acceptability of Canadian-style cigarette warning labels among US smokers and nonsmokers. Nicotine \& Tobacco Research. 9(4):473-481. [PubMed: 17454702]

Peters E, Shoots-Reinhard B, Tompkins MK, Schley D, Meilleur L, Sinayev A, Tusler M, Wagner L, Crocker J. Improving numeracy enhances STEM and decision outcomes.

Peters E, Västfjäll D, Slovic P, Mertz CK, Mazzocco K, Dickert S. 2006; Numeracy and decision making. Psychological Science. 17(5):407-413. [PubMed: 16683928] 
Petrova DG, van der Pligt J, Garcia-Retamero R. 2014; Feeling the numbers: on the interplay between risk, affect, and numeracy. Journal of Behavioral Decision Making. 27(3):191-199.

Redick TS, Shipstead Z, Harrison TL, Hicks KL, Fried DE, Hambrick DZ, Kane MJ, Engle RW. 2013; No evidence of intelligence improvement after working memory training: a randomized, placebocontrolled study. Journal of Experimental Psychology: General. 142(2):359. [PubMed: 22708717]

Reyna VF, Nelson WL, Han PK, Dieckmann NF. 2009; How numeracy influences risk comprehension and medical decision making. Psychological Bulletin. 135(6):943. [PubMed: 19883143]

Reyna VF, Weldon RB, McCormick M. 2015; Educating Intuition Reducing Risky Decisions Using Fuzzy-Trace Theory. Current Directions in Psychological Science. 24(5):392-398. [PubMed: 26594099]

Sahyoun NR, Pratt CA, Anderson AMY. 2004; Evaluation of nutrition education interventions for older adults: a proposed framework. Journal of the American Dietetic Association. 104(1):58-69. [PubMed: 14702585]

Schmeichel BJ, Vohs KD. 2009; Self-Affirmation and Self-Control. Journal of Personality and Social Psychology. 96(4):770-782. [PubMed: 19309201]

Schroy PC, Emmons K, Peters E, Glick JT, Robinson PA, Lydotes MA, Mylvanaman S, Evans S, Chaisson C, Pignone M, Prout M, Davidson P, Heeren TC. 2011; The impact of a novel computerbased decision aid on shared decision-making for colorectal cancer screening: A randomized trial. Medical Decision Making. 31(1):93-107. [PubMed: 20484090]

Shapiro JA, Seeff LC, Thompson TD, Nadel MR, Klabunde CN, Vernon SW. 2008; Colorectal cancer test use from the 2005 National Health Interview Survey. Cancer Epidemiology Biomarkers \& Prevention. 17(7):1623-1630.

Sherman DK, Cohen GL. 2006; The psychology of self-defense: Self-affirmation theory. Advances in Experimental Social Psychology. 38:183-242.

Shipstead Z, Redick TS, Engle RW. 2012; Is working memory training effective? Psychological Bulletin. 138(4):628. [PubMed: 22409508]

Sinayev A, Peters E. 2015; Cognitive reflection vs. calculation in decision making. Frontiers in Psychology. 6:532. [PubMed: 25999877]

Slovic, P. Smoking: Risk, Perception, \& Policy. London: Sage; 2001.

Smith P, Bansal-Travers M, O’Connor R, Brown A, Banthin C, Guardino-Colket S, Cummings KM. 2011; Correcting over 50 years of tobacco industry misinformation. American Journal of Preventive Medicine. 40(6):690-698. [PubMed: 21565663]

Strasser AA, Tang KZ, Romer D, Jepson C, Cappella JN. 2012; Graphic warning labels in cigarette advertisements: recall and viewing patterns. American Journal of Preventive Medicine. 43(1):4147. [PubMed: 22704744]

US Centers for Disease Control. [29 November 2016] Smoking \& Tobacco Use. 2016. http:// www.cdc.gov/tobacco/data_statistics/fact_sheets/fast_facts/

US Department of Health and Human Services. Preventing Tobacco Use Among Young People. A Report of the Surgeon General. Atlanta, Georgia: US Department of Health and Human Services, Public Health Service, Centers for Disease Control and Prevention, National Center for Chronic Disease Prevention and Health Promotion, Office on Smoking and Health; 1994.

Viscusi WK. 2000; Comment: the perils of qualitative smoking risk measures. Journal of Behavioral Decision Making. 13(2):267-272.

Ward MM, Sundaramurthy S, Lotstein D, Bush TM, Neuwelt CM, Street RL Jr. 2003; Participatory patient-physician communication and morbidity in patients with systemic lupus erythematosus. Arthritis and Rheumatism. 49(6):810-818. [PubMed: 14673968]

Weinstein ND. 1998; Accuracy of smokers' risk perceptions. Annals of Behavioral Medicine. 20(2): 135-140. [PubMed: 9989319]

Weinstein ND, Marcus SE, Moser RP. 2005; Smokers' unrealistic optimism about their risk. Tobacco control. 14(1):55-59. [PubMed: 15735301]

Weinstein ND, Slovic P, Waters E, Gibson G. 2004; Public understanding of the illnesses caused by cigarette smoking. Nicotine \& Tobacco Research. 6(2):349-355. [PubMed: 15203808]

Wilfley, D, Brownell, KD. Physical activity and diet in weight loss. In: Dishman, RK, editorAdvances in exercise adherence. Champaign, IL: Human Kinetics; 1994. 361-393. 
Zullig, LH, Shaw, RJ, Bosworth, HB. Applying technology to medication management and adherence. In: Marsch, LA, Lord, SE, Dallery, J, editorsBehavioral health care and technology: using sciencebased innovations to transform practice. New York: Oxford University Press; 2014. 81-94. 


\section{Table 1}

Five recommendations to facilitate communication

1. Carefully identify communication goals (e.g., what should the individual get out of the communication?) and plan to select evidence-based techniques so that those goals are met.

2. Include numeric information (as opposed to not providing it)

3. Reduce cognitive effort so that information can be understood and used by individuals across a range of literacy and numeracy skills.

4. Help the individual understand the affective meaning of information particularly when it is unfamiliar.

5. Draw attention to important information that evidence suggests is otherwise ignored. 